Vol. 8, Issue 12, December 2021

DOI: $10.17148 /$ IARJSET.2021.81231

\title{
MANAGEMENT of PLASTIC WASTE DISPOSAL
}

\author{
Mridula Verma \\ Associate Professor, Department of Chemistry, M.M.H College, Ghaziabad, India
}

\begin{abstract}
Plastic waste means any plastic discarded after use or after their intended use is over. Plastic wastes are rapidly produced and exposed at a high rate due to the world's industrial development and population growth. Both biodegradable and non-degradable wastes are highly generated from man-made activities (operational sectors and climatic conditions, industrial growth, socio-economic development) and the natural processes of living creatures. Government municipalities, social communities, and local authorities have established different measures and environmental safety legislation rules that can guide the population to dispose of plastic waste after utilization. In these waste management strategies, several are scientifically based, such as recycling, incineration, and landfills. These methods are established to have a clean environment and good plastic waste disposal.. The Plastic Waste Management Rules, 2016 have to be followed for the safe disposal of plastic wastes.
\end{abstract}

Keywords: Plastic waste, Recycling, Waste management, Incineration, Land filling

\section{INTRODUCTION}

The Plastic Waste Management Rules, 2016 shall apply to every waste generator, local body, Gram Panchayat, manufacturer, Importers, brand-owner, plastic waste processor (recycler, co-processor, etc.) and producer. Plastics are made up of synthetic organic polymers which are widely used in different applications ranging from water bottles, clothing, food packaging, medical supplies, electronic goods, construction materials, etc. In the last six decades, plastics became an indispensable and versatile product with a wide range of properties, chemical composition and applications. Although, plastic was initially assumed to be harmless and inert, however, many years of plastic disposal into the environment has led to diverse associated problems. Environmental pollution by plastic wastes is now recognized widely to be a major environmental burden especially in the aquatic environment where there is prolong biophysical breakdown of plastics, detrimental negative effects on wildlife, and limited plastic removal options. In many instances, sheeting and packaging plastics are disposed of after usage, however, because of their durability, such plastics are located everywhere and persistent in the environment. In human occupational and residential environment, plastics made of petrol-based polymer are present in high quantity. At the end-of-life of these plastics, they are usually land-filled. Plastics have several toxic constituents among which are phthalates, poly-fluorinated chemicals, brominated flame retardants and antimony trioxide which can leach out to have adverse effects on environmental and public health. Plastics in electronic waste (e-waste) have become a serious global environmental and public health concern due to its large production volume. The Plastic waste (Management and Handling) Rules,2011 were succeeded by the Plastic Waste Management Rules 2016 which was far more comprehensive and sought to effectively address the issue of plastic waste. This version of the rules extended its purview and applicability to rural areas and plastic importers in the supply chain.[1,2,3,4,5]

\section{REGISTRATION of PRODUCER, RECYCLERS and MANUFACTURER}

(a) No person shall manufacture carry bags or recycle plastic bags or multilayered packaging unless the person has obtained a registration from the State Pollution Control Board or the Pollution Control Committee of the Union Territory concerned or the Central Pollution Control Board, as the case may be, prior to the commencement of production.[6]

(b) Every producer or brand-owner shall, for the purpose of registration or renewal of registration, make an application, in Form 1 to,-

1. the concerned State Pollution Control Board or Pollution Control Committee of the Union territory, if operating in one or two states or Union territories; or

2. the Central Pollution Control Board, if operating in more than two States or Union Territories.[7]

(c) Every person recycling or processing waste or proposing to recycle or process plastic waste shall make an application to the State Pollution Control Board or the Pollution Control Committee, for grant of registration or renewal of registration for the recycling unit, in Form II.[5] 


\title{
International Advanced Research Journal in Science, Engineering and Technology
}

\author{
Vol. 8, Issue 12, December 2021
}

\section{DOI: $10.17148 /$ IARJSET.2021.81231}

(d) Every manufacturer engaged in manufacturer of plastic to be used as raw material by the producer shall make an application to the State Pollution Control Board or the Pollution Control Committee of the Union territory concerned, for the grant of registration or for the renewal of registration, in Form III. [5]

(e) The State Pollution Control Board or the Pollution Control Committee shall not issue or renew registration to plastic waste recycling or processing units unless the unit possesses a valid consent under the Water (Prevention and Control of Pollution) Act, 1974 (6 of 1974) and the Air (Prevention and Control of Pollution) Act, 1981 (14 of 1981) along with a certificate of registration issued by the District Industries Centre or any other Government agency authorised in this regard.[5]

(f) The State Pollution Control Board or the Pollution Control Committee shall not renew registration of producer unless the producer possesses and action plan endorsed by the Secretary in charge of Urban Development of the concerned State or Union Territory for setting of plastic waste management system.

(g) On receipt of the application complete in all respects for the registration for recycling or processing of plastic waste under sub-rule (c), the State Pollution Control Board may, after such inquiry as it considers necessary and on being satisfied that the applicant possesses appropriate facilities, technical capabilities and equipment to handle plastic waste safely, may grant registration to the applicant on fulfillment of the conditions as may be laid down in terms of registration.[5]

(h) Every State Pollution Control Board or Pollution Control Committee shall take a decision on the grant of registration within ninety days of receipt of an application which is complete in all respects.

(i) The registration granted under this rule shall initially be valid for a period of one year, unless revoked, suspended or cancelled and shall subsequently be granted for three years.

(j) ) State Pollution Control Board or the Pollution Control Committees shall not revoke, suspend or cancel registration without providing the opportunity of a hearing to the producer or person engaged in recycling or processing of plastic wastes.

(k) Every application for renewal of registration shall be made at least one hundred twenty days before the expiry of the validity of the registration certificate.

\section{A. RESPONSIBILITY of WASTE GENERATOR}

\section{RESPONSIBILITIES}

(a) The waste generator shall take steps to minimize generation of plastic waste and segregate plastic waste at source in accordance with the Solid Waste Management Rules, 2000 or as amended from time to time.

(b) The waste generator shall not litter the plastic waste and ensure segregated storage of waste at source and handover segregated waste to urban local body or gram panchayat or agencies appointed by them or registered waste pickers', registered recyclers or waste collection agencies.

(c) All institutional generators of plastic waste, shall segregate and store the waste generated by them in accordance with the Municipal Solid Waste (Management and Handling) Rules, 2000 notified vide S.O 908(E) dated the 25th September, 2000 under the Act or amendment from time to time and handover segregated wastes to authorized waste processing or disposal facilities or deposition centers either on its own or through the authorized waste collection agency.[5]

(d) All waste generators shall pay such user fee or charge as may be specified in the byelaws of the local bodies for plastic waste management such as waste collection or operation of the facility thereof, etc.

\section{B. RESPONSIBILITY of PRODUCERS, IMPORTERS ANd BRAND OWNERS}

(a) The producers, within a period of six months from the date of publication of these rules, shall work out modalities for waste collection system based on Extended Producers Responsibility and involving State Urban Development Departments, either individually or collectively, through their own distribution channel or through the local body concerned as per guidelines issued under these rules from time to time.[6]

(b) Primary responsibility for collection of used multi-layered plastic sachet or pouches or packaging is of Producers, Importers and Brand Owners who introduce the products in the market. They need to establish a system for collecting back the plastic waste generated due to their products. This plan of collection to be submitted to the State Pollution Control Boards while applying for Consent to Establish or Operate or Renewal. The Brand Owners whose consent has been renewed before the notification of these rules shall submit such plan within one year from the date of notification of these rules and implement with two years thereafter.

(c) Manufacturer and use of multi-layered plastic which is non-recyclable or non-energy recoverable or with no alternate use should be phased out in two years time.[7]

(d) The producer, within a period of three months from the date of final publication of these rules in the Official Gazette shall apply to the Pollution Control Board or the Pollution Control Committee, as the case may be, of the States or the Union Territories administration concerned, for grant of registration 
Vol. 8, Issue 12, December 2021

\section{DOI: 10.17148/IARJSET.2021.81231}

(e). No producer shall on and after the expiry of a period of Six Months from the date of final publication of these rules in the Official Gazette manufacture or use any plastic or multilayered packaging for packaging of commodities without registration from the concerned State Pollution Control Board or the Pollution Control Committees.

(f) Every producer shall maintain a record of details of the person engaged in supply of plastic used as raw material to manufacture carry bags or plastic sheet or like or cover made of plastic sheet or multilayered packaging. [5]

\section{RESPONSIBILITY of LOCAL BOADY}

(a) Every local body shall be responsible for development and setting up of infrastructure for segregation, collection, storage, transportation, processing and disposal of the plastic waste either on its own or by engaging agencies or producers..

(b). The local body shall be responsible for setting up, operationalisation and coordination of the waste management system and for performing the associated functions, namely

(1) Ensuring segregation, collection, storage, transportation, processing and disposal of plastic waste.

(1a) Ensuring that the provisions of these rules, as amended, are adhered to. [6]

(2) Ensuring that no damage is caused to the environment during this process.

(3) Ensuring channelization of recyclable plastic waste fraction to recyclers.

(4) Ensuring processing and disposal on non-recyclable fraction of plastic waste in accordance with the guidelines issued by the Central Pollution Control Board.[5]

(5) Creating awareness among all stakeholders about their responsibilities.

(6) Engaging civil societies or groups working with waste pickers.

(7) Ensuring that open burning of plastic waste does not take place.

(c) The local body for setting up of system for plastic waste management shall seek assistance of producers and such system shall be set up within one year from the date of final publication of these rules in the Official Gazaette of India.[5]

(d) The local body to frame bye-laws incorporating the provisions of these rules.

\section{RESPONSIBILITY of GRAM PANCHAYAT}

(a) Every gram panchayat either on its own or by engaging an agency shall set up, operationalise and co-ordinate for waste management in the rural area under their control and for performing the associated functions, namely;

(1) Ensuring segregation, collection, storage, transportation, plastic waste and channelization of recyclable plastic waste fraction to recyclers having valid registration; ensuring that no damage is caused to the environment during this process.[5]

(1a) Ensuring that the provisions of these rules, as amended, are adhered to.[6]

(2) Creating awareness among all stakeholders about their responsibilities.

(3) Ensuring that open burning of plastic waste does not take place.

\section{E. RESPONSIBILITY of RETAILERS and STREET VENDORS}

(a) Retailers or street vendors shall not sell or provide commodities to consumer in carry bags or plastic sheet or multilayered packaging, which are not manufactured and labelled or marked, as per prescribed under these rules.[5].

(b) Every retailers or street vendors selling or providing commodities in, plastic carry bags or multilayered packaging or plastic sheets or like or covers made of plastic sheets which are not manufactured or labelled or marked in accordance with these rules shall be liable to pay such fines as specified under the bye-laws of the local bodies.

\section{TYPES OF PLASTIC}

There are different types of plastics based on their constituents and type of materials used in their production. [ 5,8 ]

\section{A. POLYETHYLENE TEREPHTHALATE (PET)}

It is clear, tough, solvent resistant, barrier to gas and moisture, softens at $80{ }^{\circ} \mathrm{C}$.

\section{B. HIGH DENSITY POLYETHYLENE (HDPE)}

It is hard to semi-flexible, resistant to chemicals and moisture, waxy surface, opaque, softens at $75{ }^{\circ} \mathrm{C}$, easily coloured, processed and formed.

\section{POLYVINYL CHLORIDE (PVC)}

It is strong, tough, softens at $80^{\circ} \mathrm{C}$, can be clear and can be solvent welded.

D. LOW DENSITY POLYETHYLENE (LDPE)

It is Soft flexible, waxy surface, translucent, softens at $70^{\circ} \mathrm{C}$, scratches easily. E. POLYPROPYLENE (PP)

It is hard and translucent, soften at $140{ }^{\circ} \mathrm{C}$, translucent, withstands solvents, versatile. 
Vol. 8, Issue 12, December 2021

DOI: $10.17148 /$ IARJSET.2021.81231

\section{F. POLYSTYRENE (PS)}

It is clear, glassy rigid, opaque, semi tough, soften at $95{ }^{\circ} \mathrm{C}$, Affected by fat, acids and solvents, but resistant to alkalis, salt solutions, Low water absorption, when not pigmented is clear and taste free.

\section{G. OTHER}

It includes all resins and multimaterials (e.g. laminates), properties dependent on plastic or combination of plastics.

\section{PLASTIC WASTE MANAGEMENT}

(a) The plastic waste management by the urban local bodies in their respective jurisdiction shall be as under.

(1) Plastic waste, which can be recycled, shall be channelized to registered plastic waste recycler and recycling of plastic shall conform to the Indian Standard: IS 14534:1998 titled as Guidelines for Recycling of Plastics, as amended from time to time. [5]

(2) Local bodies shall encourage the use of plastic waste (preferably the plastic waste which cannot be further recycled) for road construction as per Indian Road Congress guidelines or energy recovery or waste to oil etc. The standards and pollution control norms specified by the prescribed authority for these technologies shall be complied with.[5]

(3) Thermo set plastic waste shall be processed and disposed off as per the guidelines issued from time to time by the Central Pollution Control Board.

(4) The inert from recycling or processing facilities of plastic waste shall be disposed of in compliance with the Solid Waste Management Rules, 2016 or as amended from time to time [6]

\section{PROTOCOLS for COMPOSTABLE PLASTIC MATERIALS}

Determination of the degree of degradability and degree of disintegration of plastic material shall be as per the protocols of the Indian Standards listed in Schedule-I to these rules. [5]

\section{MARKING or LABELLING}

(a) Each plastic carry bag, plastic packaging and multilayered packaging shall have the following information printed in English namely. [6]

(1) Name, registration number of the manufacturer, producer or brand owner and thickness in case of carry bag and plastic packaging used by the brand owner. [6]

(2) Name and registration number of the manufacturer in case of multilayered packaging; excluding multi-layered packaging used for imported goods.[6]

(3) Name and certificate number of producer [Rule 4(h)] in case of carry bags made from compostable plastic. [6]

(b) Each recycled carry bag shall bear a label or a mark recycled and shall conform to the Indian Standard: IS 14534: 1998 titled as Guidelines for Recycling of Plastics, as amended from time to time. Each carry bag made from compostable plastics shall bear a label "compostable" and shall conform to the Indian Standard : IS or ISO 17088:2008 titled as Specifications for Compostable Plastics.[5]

\section{TREATMENT AND DISPOSAL METHODS OF PLASTIC WASTE}

Methods for the treatment and disposal of Plastic waste are as follows.

\section{A. LAND FILLING}

Land filling is the waste management conventional approach in many countries, however, scarcity of space for landfills is becoming a major problem. There is a growing environmental and public health concern about the potential effects of landfills because of the types and quantities of toxic chemicals and their potential for leaching at landfill sites. Landfills refer to all places and areas where we reject all disposable plastic waste after utilization before being buried under the earth's face. Precautionary measures should be applied to avoid secondary side effects like groundwater contaminants and soil degradation that can result from poor disposal processing. The objectives of landfill arrangement are to provide a safer area of plastic waste disposal to protect all dimensions of the environment, i.e., aquatics and airspace, to achieve the objectives mentioned above. It demands a lot of work be done in the community, like digging a long hole or dumping in high depths and putting waste into it and letting them decompose. This process is completed very slowly, as it can take more than a year. During this landfills processing, each organic molecule pass through biodegradation and decomposition. Different plastic wastes can take a long time of degradation due to their specific biochemical properties and environmental or climate conditions like sunlight, wind, and climate change. Landfills are an excellent energy source due to the carbon dioxide and methane gas produced during the biodegradation process. It is a cost-effective method of plastic waste management. Although this method can be used to treat plastics wastes, it has some disadvantages, including being partially responsible for climate change and lighting up methane as combustible gas. It contaminates soil and water and affects wildlife. Environmental pollution and risks to public health can be reduced if the landfills are well-managed.[9,10,11] 
International Advanced Research Journal in Science, Engineering and Technology

Vol. 8, Issue 12, December 2021

DOI: 10.17148/IARJSET.2021.81231

\section{B. INCINERATION}

An alternative to land filling of plastic waste is incineration This method refers to the burning of wastes in oxygen, which is chemically known as complete combustion that releases water molecules and carbon dioxide into the atmosphere. There is growing concerns exist about the potential atmospheric release of hazardous chemicals during the process. For instance, plastic waste fumes release halogenated additives and polyvinyl chloride, while furans, dioxins, and polychlorinated biphenyls are released from incineration of plastics into the environment. The waste produced after incineration is composed of different volatile chemicals, ash, and a small amount of hydrochloric acid. All plastic waste is not a good candidate for combustion; some are resistant to oxygen heating and explosives. The combustion of organic molecules can also produce energy which is known as fuel. Incineration method has several different positive impacts on society rather than energy production. It also has huge contributions in minimizing waste and producing electricity from the waste, which is highly needed in modern industrialisation. There are several benefits of plastic waste management through incineration. These include decreased quantity of waste in the ecosystem, produces heat and power needed in different activities, reduces pollution of the atmosphere, saves economy on transport fee of the waste, and emilites harmful germs and chemicals. Incineration process has benefits and drawbacks like all other biochemical processes or scientific processes. It pollutes the environment and can damage public health. It releases ash waste that can harm people and the environment.[12,13]

\section{RECYCLING}

Reprocessing of recovered plastic scraps or wastes into usable products is called plastic recycling. Most plastics are non-biodegradable in nature, hence, the fundamental work is reduction of waste emissions, effective management and recycling of resulting wastes.. This process is performed in the following six steps: collecting waste plastics, sorting, or arranging plastics into categories, washing to remove impurities, shredding and resizing, identifying and separating plastics, and compounding. There are four main categories of recycling which are: primary (which involves the mechanical reprocessing of plastics into a new product with equivalent properties), secondary (which involves the mechanical reprocessing of plastics into a product with lower properties), tertiary (which involves the recovery of the chemical constituents of the plastics) and quaternary (which involves energy recovery from the plastics). There are several benefits of plastic waste recycling that the world can gain when plastic are reused rather than disposing of them in non-desirable places, one of the advantages is the protection of human life by decreasing carbon dioxide and other harmful gases in the atmosphere, which can occur during incineration or combustion of the wastes .Recycling reduces pollution across in ecosystem, requires less energy, and helps in natural conservation. It saves fast-depleting landfill space and eases the demand for fossil fuel consumption. Moreover, it promotes a sustainable lifestyle and contributes to the national economy. Although recycling has different benefits to the community, it also has some disadvantages that can be managed and controlled. During the recycling process, some chemicals are released into the environment..Among these chemicals, some are volatile gases that come from plastic waste compositions and organic chain of monomers that build up a plastic chain of organic fumes and ashes, which kill plant structure and affect wildlife when inhaled by different animals that live near the recycling zone. As the process requires heat to melt plastics, it also generates sulfur, carbon, and other gases emitted to the environment. These gases can cause global warming, greenhouse effect, and acidic rain that harm the environment in different ways. $[14,15,16]$

\section{ANNUAL REPORTS}

(a) Every person engaged in recycling or processing of plastic waste shall prepare and submit an annual report in FormIV to the local body concerned under intimation to the concerned State Pollution Control Board or Pollution Control Committee by the 30th April, of every year.[5]

(b) Every local body shall prepare and submit an annual report in Form $-\mathrm{V}$ to the concerned Secretary-in-charge of the Urban Development Department under intimation to the concerned State Pollution Control Board or Pollution Control Committee by the 30th June, every year.

(c) Each State Pollution Control Board or Pollution Control Committee shall prepare and submit an annual report in Form VI to the CPCB on the implementation of these rules by the 31 st July, of every year.

(d) The CPCB shall prepare a consolidated annual report on the use and management of plastic waste and forward it to the Central Government along with its recommendations before the 31st August of every year.. 


\title{
International Advanced Research Journal in Science, Engineering and Technology
}

\author{
Vol. 8, Issue 12, December 2021
}

\section{DOI: $10.17148 /$ IARJSET.2021.81231}

\section{CONCLUSION}

The Plastic wastes have constituted a major environmental issue. Although plastics have several important roles in our lives due to their physicochemical composition, they can cause different problems to human life and the ecosystem if the post-use disposal is not well-managed. In this study, the focus was on the management of plastic waste disposal. We have discussed the functional elements involved in plastic waste management (i.e. procedure of registration, responsibilities, types of plastic, management of plastic wastes, protocol for compostable plastic material, marking or labelling, treatment, disposal, and annual report). Subsequently we explained the methods of Plastic wastes disposal through land filling, incineration and recycling to reduce their impact on public health and the environment. The result of the study demonstrate the need for strict enforcement of legal provisions and a better environment system for the disposal of plastic waste. Provision of a plastic waste management planning and monitoring system is a prerequisite issue for effective reduction of plastic waste associated risks.

\section{REFERENES}

[1]. Proshad R, Islam MS, Kormoker T, Haque MA, Mahfuzur Rahman MD, et al. (2018) Toxic effects of plastic on human health and environment: A consequences of health risk assessment in Bangladesh Inter J Hlth 6: 1-5.

[2]. Rochman CM, Browne MA, Halpern BS, Hentschel BT, Hoh E, et al. (2013a) Policy: Classify plastic waste as hazardous. Nature 494: $169-171$.

[3]. Joint Group of Experts on the Scientific Aspects of Marine Environmental Protection (GESAMP) (2016) Sources, fate and effects of microplastics in the marine environment: Part Two of a Global Assessment. Int Mar Org, London.

[4]. Derraik JG (2002) The pollution of the marine environment by plastic debris: A review. Mar Pollut Bull 44: 842-852.

[5]. Gazette of India. GSR.320 (E) dated 18 March 2016, Plastic Waste Management Rules, 2016, Ministry of Environment, Forests and Climate Change, Government of India, New Delhi, India. 2016, 1-22.

[6 ]. Gazette of India. GSR. 571(E) dated 12 August 2021, Plastic Waste Management (Amendment) Rules, 2021, Ministry of Environment, Forests and Climate Change, Government of India, New Delhi, India. 2021.

[7]. Gazette of India. GSR. 285 (E) dated 27 March 2018, Plastic Waste Management (Amendment) Rules, 2018, Ministry of Environment, Forests and Climate Change, Government of India, New Delhi, India. 2018.

[8]. Alhazmi, H,;Almansour,F.H.;Aldhafeeri,Z. Plastic Waste Management: A Review of Existing Life Cycle. Sustainability 2021, 13, 5340 .

[9]. Y. Liang, Q. Tan, Q. Song, J. Li, An analysis of the plastic waste trade and management in Asia. Waste Manag., 119 (2021), pp. $242-253$.

[10]. Y. Zheng, E.K. Yanful, A.S. Bassi, A review of plastic waste biodegradation, Crit. Rev. Biotechnol., 25 (4) (2005), pp. 243-250.

[11]. C. Zhou, W. Fang, W. Xu, A. Cao, R. Wang, Characteristics and the recovery potential of plastic wastes obtained from landfill mining, J. Clean. Prod., 80 (2014), pp. 80-86.

[12]. R. Shome, Role of microbial enzymes in Bioremediation, eLifePress, 1 (2020), pp. 15-20.

[13]. C. Netzer, T. Li, T. Løvås, Surrogate reaction mechanism for waste incineration and pollutant formation, Energy Fuels (2021), pp. 1-11.

[14]. E. Szostak, P. Duda, A. Duda, N. Górska, A. Fenicki, P. Molski, Characteristics of plastic waste processing in the modern recycling plant operating in Poland, Energies, 14 (1) (2021), p. 35.

[15]. I. Vollmer, M.J. Jenks, M.C. Roelands, R.J. White, T. van Harmelen, P. de Wild, B.M. Weckhuysen, Beyond mechanical recycling: giving new life to plastic waste, Angew. Chem. Int. Ed., 59 (36) (2020), pp. 15402-15423.

[16]. L. Shen, E. Worrell, Plastic recycling, Handbook of Recycling, Elsevier (2014), pp. 179-190. 